\title{
Analyzing the effects of thermal stress on insulator papers by solid-state ${ }^{13} \mathrm{C}$ NMR spectroscopy
}

\author{
Paul Jusner (1) - Markus Bacher $(\mathbb{D} \cdot$ Jonas Simon $(\mathbb{D})$ Florian Bausch $(\mathbb{D} \cdot$ \\ Hajar Khaliliyan (D) Sonja Schiehser (D) - Ivan Sumerskii (i) Elisabeth Schwaiger • \\ Antje Potthast $(\mathbb{D} \cdot$ Thomas Rosenau $[$ (D)
}

Received: 12 September 2021/Accepted: 15 November 2021/Published online: 29 November 2021

(C) The Author(s) 2021

\begin{abstract}
Million tons of cellulosic paper have been used for insulating coils in oil-filled electrical power transformers, thereby assuring the electricity supply for our societies. The high working temperatures in transformers constantly degrade paper insulators throughout their service life of up to 40 years. We approached the structural changes in oil-immersed cellulosic paper samples upon thermal stress in a study that compared unbleached softwood Kraft paper used as insulator paper with pure cotton cellulose paper. The model experiments used a thermal treatment in transformer oil at $170{ }^{\circ} \mathrm{C}$ for up to 14 days. The
\end{abstract}

Supplementary Information The online version contains supplementary material available at https://doi.org/10.1007/ s10570-021-04338-z.

P. Jusner · M. Bacher · J. Simon .

F. Bausch $\cdot$ H. Khaliliyan - S. Schiehser .

A. Potthast · T. Rosenau ( $\square)$

Department of Chemistry, Institute of Chemistry of Renewable Resources, University of Natural Resources and Life Sciences Vienna (BOKU), Konrad-Lorenz-

Straße 24, 3430 Tulln, Austria

e-mail: thomas.rosenau@boku.ac.at

I. Sumerskii

Core Facility Analysis of Lignocellulosics, University of

Natural Resources and Life Sciences Vienna (BOKU),

Konrad-Lorenz-Straße 24, 3430 Tulln, Austria

E. Schwaiger

Mondi Frantschach GmbH, Frantschach 5,

9413 St. Gertraud, Austria samples were characterized by means of ${ }^{13} \mathrm{C} \mathrm{CP} / \mathrm{MAS}$ NMR spectroscopy, mainly based on deconvolution of the $\mathrm{C} 4$ resonance. An automated, fast, and reproducible $\mathrm{C} 4$ resonance deconvolution employing the "Peak Analyzer" tool of OriginPro 2020 (OriginLab Corporation, USA) was developed and used to exploit ${ }^{13} \mathrm{C}$ CP/MAS NMR spectroscopy for the characterization of thermally stressed paper samples. Our results show that thermally induced structural changes depend heavily on the composition of paper, that hornification and coalescence of fibrils take place, and that the allomorph composition of cellulose crystallites is altered under the given conditions.

\author{
T. Rosenau \\ Johan Gadolin Process Chemistry Centre, Åbo Akademi \\ University, Porthansgatan 3, 20500 Turku, Finland
}




\section{Graphical abstract}
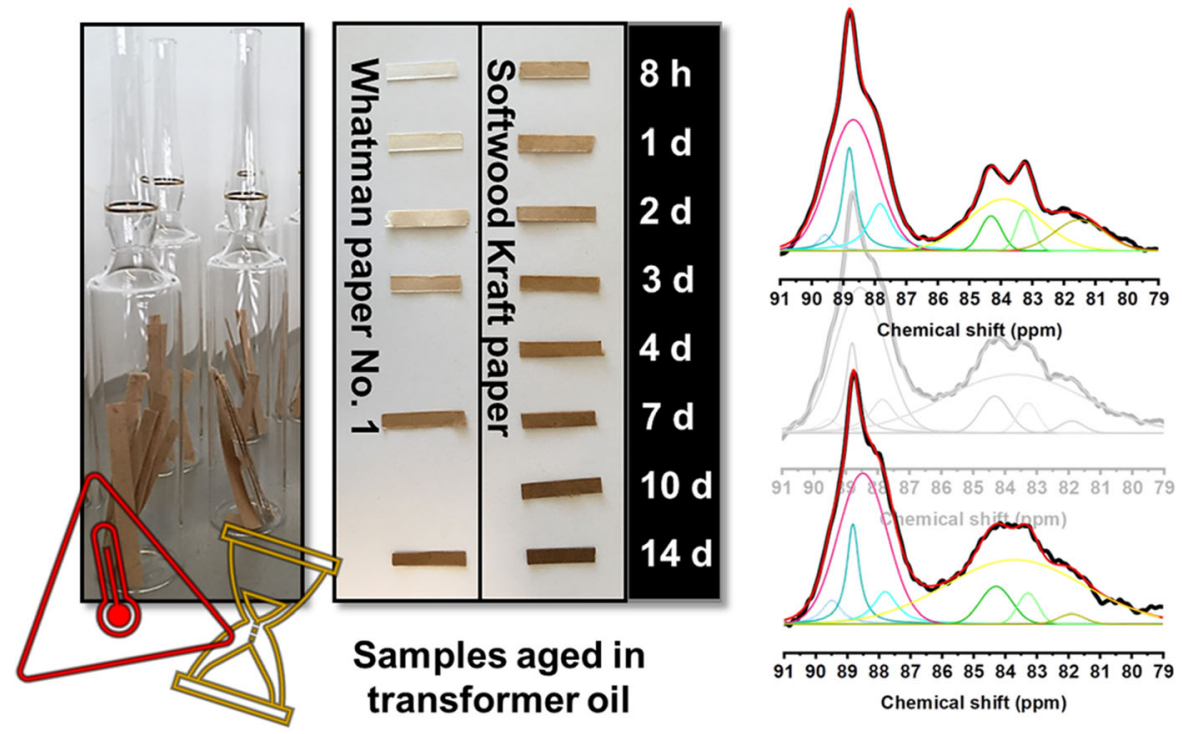

Keywords Cellulose - Solid-state structure · Insulator paper · Solid-state ${ }^{13} \mathrm{C} \mathrm{CP/MAS} \mathrm{NMR}$ spectroscopy $\cdot$ Thermal stress $\cdot$ Paper aging

\section{Introduction}

A sound understanding of the complex processes that occur during degradation of cellulose that has been exposed to elevated temperatures is of importance to ensure the electricity supply for our societies. This is because engineers have been relying since decades on oil-immersed cellulosic paper as insulators in high voltage power cables, condenser bushings, and, most importantly, electrical power transformers (Prevost and Oommen 2006). Paper has proved to be competitive with synthetic materials due to its outstanding combination of satisfactory insulating performance in dry state, good mechanical properties at high temperatures, and-last but not least-its low price. In electrical power transformers, the insulation paper is wrapped around copper coils to insulate them from the magnetic core. Paper pressboards additionally serve as mechanical support. The entire assembly of core, coils, and paper insulators is immersed in transformer oil to exclude oxygen and water as far as possible as well as to enhance heat dissipation. Under normal working conditions, temperatures in power transformers stay within the range of $65-95^{\circ} \mathrm{C}$ (Emsley and Stevens 1994b). However, in case of unexpected, heavy loads or failure of the cooling system, the transformers' working temperature easily surpasses the design values. Partial discharges even may cause locally restricted short-time temperature peaks of $1000{ }^{\circ} \mathrm{C}$ ( $\mathrm{Li}$ et al. 2020). Despite these harsh conditions and if operated properly, oil-immersed paper insulation systems last for up to 40 years without replacement (Jalbert et al. 2014). and thus are an important pillar that our societies' electrical energy supply is resting on.

Nonetheless, the complex degradation behavior of cellulosic materials exposed to high temperatures poses a challenge to electrical engineers as well as to analytical chemists. Given that direct sampling of the oil-immersed paper in the insulation system of an operating transformer is difficult, assessing the insulator condition based on analysis of paper decomposition products accumulated in the oil has become a topic of interest for engineers and chemists (Emsley and Stevens 1994b; Scheirs et al. 1998; Emsley et al. 2000a; Jalbert et al. 2014). The transformer oils are highly hydrophobic and largely inert under the standard operating conditions, and do hardly react with 
cellulose. This system is thus in contrast to solutions or suspensions commonly used in cellulose chemistry, where the medium can unfold a rich byproduct chemistry that can lead to solvent degradation (Liebner et al. 2010; Chrapava et al. 2003) cellulose derivatization (Potthast et al. 2002; Rosenau et al. 2004) or rapid cellulose degradation (Rosenau et al. 1999). Many model experiments have been conducted to clarify the correlation of cellulose degradation and the corresponding degradation products in the transformer oil of aged systems over time and in dependence on the conditions (Scheirs et al. 1998; Emsley et al. 2000a, 2000b; Soares et al. 2001; Lundgaard et al. 2004; Jalbert et al. 2014; Arroyo-Fernandez et al. 2017). The number of studies focusing on the changes of the thermally stressed paper itself, instead of the analysis of its degradation products, is much lower, and also methods applied to characterize these aged paper samples are not really diverse. Mostly, mechanical tests, viscosimetric determination of the degree of polymerization of cellulose, some size exclusion chromatography (SEC) analysis, and Fourier-transformed infrared spectroscopy (FTIR) have been carried out to study the thermal stress of oil-immersed cellulose and paper in transformer insulators. We found that there is a lack of direct information on the supramolecular, structural changes occurring during this thermal aging, and solid-state ${ }^{13} \mathrm{C}$ nuclear magnetic resonance (NMR) spectroscopy appeared as suitable analytical means to address this issue.

Certainly, exposure to elevated temperatures, especially over prolonged periods of time, will affect the structural and supramolecular arrangement of the cellulose polymer in paper. Hornification-still a rather ill-defined term-upon drying or coalescence of microfibrils upon ageing of paper and pulp fibers has been frequently described as a possible consequence (Kato and Cameron 1999; Fernandes Diniz et al. 2004; Pönni et al. 2012). These thermally induced processes are known to significantly reduce the hydroxyl group accessibility and reactivity of cellulosic structures. Additionally, thermally induced structural changes within the crystallite core of cellulose samples immersed in different media have been observed for temperatures between 220 and $280{ }^{\circ} \mathrm{C}$ (Yamamoto et al. 1989; Debzi et al. 1991). We wanted to explore if and to what extent such phenomena occur in oil-immersed insulation paper at temperatures typically prevailing in power transformers.
The crystallinity of cellulose is known to affect the kinetics of thermal degradation processes in paper insulators: the crystalline structure determines mechanical properties of cellulose fibrils (Emsley and Stevens 1994a) and the crystallite size of cellulose directly affects the onset temperature of the thermal decomposition (Kim et al. 2010). Solid-state ${ }^{13}$ C CP/ MAS NMR is a powerful tool for the characterization of cellulose crystallites, their organization in crystallite bundles, distinction of cellulose allomorphs as well as crystalline and non-crystalline contributors. Especially the resonance of $\mathrm{C} 4$ of anhydroglucose units in cellulose reveals structural information in great detail. Already Vanderhart and Atalla (1984) studied the solid-state structure of cellulose by means of this method which proved to be sensitive enough to distinguish between two native cellulose contributors, allomorph I $\alpha$ and allomorph I $\beta$ (Atalla and Vanderhart 1984). Since then, this method has been further advanced and deconvolution models of the $\mathrm{C} 4$ resonance (79-91 ppm) of ${ }^{13} \mathrm{C}$ CP/MAS NMR spectra have been elaborated to address the supramolecular architecture of cellulosic samples in detail (Yamamoto and Horii 1993; Larsson et al. 1997, 1999; Wickholm et al. 1998; Zuckerstätter et al. 2009, 2013). We adapted these models for an automated, fast, and reproducible $\mathrm{C} 4$ resonance deconvolution employing the "Peak Analyzer" tool of OriginPro 2020 (OriginLab Corporation, USA) and employed it to study the structural changes in the thermally stressed paper samples. The paper specimens were immersed in transformer oil and subjected to $170{ }^{\circ} \mathrm{C}$ for up to 14 days. For comparison, original insulator paper sheets (unbleached softwood Kraft pulp containing residual lignin and hemicelluloses) and paper from pure cellulose (cotton fibers) were used. The oilimmersed samples were characterized in regular intervals by means of ${ }^{13} \mathrm{C}$ CP/MAS NMR spectroscopy and the low molecular weight monosaccharide composition was quantified via acidic methanolysis.

\section{Material and methods}

Sample preparation

Handsheets were prepared from a softwood Kraft pulp (Kappa number 38, hemicellulose content of 
$93.56 \pm 0.36 \mu \mathrm{g} / \mathrm{mg}$ ) on a Rapid Köthen sheet former. The pulp was kindly supplied by Mondi Frantschach GmbH, Austria. The softwood Kraft paper (SWKP) sheets and Whatman paper No. 1 (WP, pure cotton cellulose) were cut into stripes (width $=5 \mathrm{~mm}$, maximum length $=2.5 \mathrm{~cm}$, with ceramic scissors) and transferred into $20 \mathrm{~mL}$ prescored borosilicate glass ampoules $(0.125 \mathrm{~g}$ per sample). SWKP and WP had a grammage of $87 \mathrm{~g} / \mathrm{m}^{2}$. Before closing the ampoules, the samples were dried for $72 \mathrm{~h}$ at $40{ }^{\circ} \mathrm{C}$ in a vacuum oven and subsequently stored in a desiccator for $48 \mathrm{~h}$ over $\mathrm{P}_{4} \mathrm{O}_{10}$ with vacuum applied. Then, the desiccator was flushed with Ar for 5 min and $10 \mathrm{~g}$ of dry Nynas Nytro 4000X transformer oil (Nynas AB, Sweden) were added to each sample. The desiccator was evacuated until no bubbles rising from the oil were visible anymore and flushed with Ar again. The ampoules were sealed by melting off the necks. The samples were aged at $170{ }^{\circ} \mathrm{C}$ for up to 14 days, sampling for SWKP after 0, 0.3, 1, 2, 3, 4, 7, 10, and 14 days; sampling for WP after $0,0.3,1,2,3$, 7 , and 14 days. Before further analysis, the transformer oil was removed by accelerated solvent extraction (ASE) with $n$-heptane at around $115 \mathrm{bar}$ and $40{ }^{\circ} \mathrm{C}$ for $2 \mathrm{~h}$.

\section{Lignin isolation}

Lignin was isolated from a black liquor sample supplied by Mondi Frantschach $\mathrm{GmbH}$, Austria, by means of acid precipitation according to Balakshin and Capanema (2015). The black liquor was obtained from the same pulp mill where the softwood Kraft pulp used in this study was produced.

\section{${ }^{13} \mathrm{C}$ CP/MAS NMR}

Solid state ${ }^{13} \mathrm{C}$ cross-polarization/magic angle spinning (CP/MAS) NMR spectra were recorded on a Bruker Avance III HD 400 spectrometer (Bruker, Germany) with a resonance frequency of $400.13 \mathrm{MHz}$ for ${ }^{1} \mathrm{H}$ and $100.61 \mathrm{MHz}$ for ${ }^{13} \mathrm{C}$. The system was equipped with a $4 \mathrm{~mm}$ dual broadband CP/MAS probe. ${ }^{13} \mathrm{C}$ spectra were recorded at room temperature $\left(20{ }^{\circ} \mathrm{C}\right)$ by applying either the total sideband suppression (TOSS) sequence with a MAS rate of $5 \mathrm{kHz}$ or the direct $\mathrm{CP}$ sequence at $12 \mathrm{kHz}$. In both cases a $\mathrm{CP}$ contact time of $2 \mathrm{~ms}$, a recycle delay of $2 \mathrm{~s}$, and SPINAL-64 ${ }^{1} \mathrm{H}$ decoupling was used. The acquisition time was set to $49 \mathrm{~ms}$, and the spectral width was fixed to $250 \mathrm{ppm}$. All ${ }^{13} \mathrm{C}$ chemical shifts were referenced externally against the carbonyl signal of glycine at $176.03 \mathrm{ppm}$. The samples were swollen in deionized water overnight before recording the spectra.

Deconvolution of the $\mathrm{C} 4$ resonance (91-79 ppm) was carried out according to Wickholm et al. (1998) and Zuckerstätter et al. (2013) by using the "Peak Analyzer" tool of the OriginPro 2020 software (OriginLab Corporation, USA) which allows nonlinear least-squares fitting. Peak positions were defined according to Zuckerstätter et al. (2013) and peak shapes as well as peak widths were implemented according to Wickholm et al. (1998). The deconvolution model for SWKP featured 8 peaks-including a hemicellulose peak-whereas the deconvolution model for WP featured only 7 peaks (no hemicellulose contribution). The settings for the "Peak Analyzer" and peak constraints are described in detail in section 1 of the Supplementary Information.

Crystallinity indices $(C I)$ were obtained by relating the sum of fitted curve integrals contributing to the crystalline part of the $\mathrm{C} 4$ resonance of cellulose $[\mathrm{I} \alpha$, $\mathrm{I} \beta, \mathrm{I} \alpha \beta$, paracrystalline signal (PC)] to the sum of all fitted curve integrals contributing to the $\mathrm{C} 4$ resonance $[\mathrm{I} \alpha, \mathrm{I} \beta, \mathrm{I} \alpha \beta, \mathrm{PC}$, accessible surface I (ASI), accessible surface II (ASII), inaccessible surface (IAS)], but excluding the hemicellulose $\mathrm{C} 4$ signal (HC). The lateral crystallite dimensions $(L D)$ were calculated according to Eq. (1) published by Newman (1999) inserting $C I$ and the average surface layer distance of cellulose chains $(d)$ derived from the 24 chain crystallite model suggested by Oehme et al. (2015). For further information, see section 4 of the supplementary information.

$L D=(2 * d) /\left(1-C I^{0.5}\right)$

$L D$ lateral crystallite dimension, $d$ average layer distance, $C I$ crystallinity index.

The fitted curves (red solid lines) in Figs. 3, 4, 5, 6 and 7 were obtained with the "Nonlinear Curve Fit" tool of OriginPro 2020. The fits were optimized through the least-square Levenberg-Marquardt algorithm. For the sake of simplicity, we applied only exponential growth, exponential decay, and linear functions, as well as combinations thereof. Red data points in Figs. 4, 5 and 6 are obvious outliers, presumably caused by weighing errors, minute 
contamination during sheet formation and ASE, or by artefacts in the analyzed spectrum.

Acidic methanolysis and monosaccharide quantification by gas chromatography (GC-FID)

The composition of low-molecular weight carbohydrates was quantified according to Sundberg et al. (1996) and Becker et al. (2021). All solvents used were commercially obtained and of highest purity available. 8-9 mg of freeze-dried sample material were weighed into a $10 \mathrm{~mL}$ test tube (in duplicate). $4 \mathrm{~mL}$ of a $2 \mathrm{M}$ $\mathrm{HCl}$ solution in anhydrous methanol were added, vortexed for $2 \mathrm{~min}$ at $\mathrm{RT}$, and heated to $100{ }^{\circ} \mathrm{C}$ for $5 \mathrm{~h}$. Every $15 \mathrm{~min}$ the samples were vortexed. After the samples were cooled to RT, $0.4 \mathrm{~mL}$ of anhydrous pyridine was added, followed by another vortex treatment. $0.2 \mathrm{~mL}$ of a D-sorbitol solution in anhydrous methanol (c $=5 \mathrm{mg} / \mathrm{mL}$, purity $\geq 98 \%$, Sigma Aldrich, Germany) were added as an internal standard. The methanol was evaporated under a constant $\mathrm{N}_{2}$ stream overnight. Afterwards, $0.2 \mathrm{~mL}$ of anhydrous pyridine were added, the samples were vortexed, and left for equilibration for $1 \mathrm{~h}$. $0.2 \mathrm{~mL}$ of anhydrous pyridine containing $1.5 \mathrm{mg}$ of 4-(dimethylamino)pyridine (purity $\geq 99 \%$, Sigma Aldrich, Germany) per $\mathrm{mL}$ of pyridine was added as well as $0.4 \mathrm{~mL}$ of $\mathrm{N}, \mathrm{O}$-bis(trimethylsilyl)-trifluoroacetamide (purity $\geq 99 \%$, Sigma Aldrich, Germany) containing $10 \%$ trimethyl-chlorosilane (purity $\geq 99 \%$, Sigma Aldrich, Germany). The samples were vortexed at $\mathrm{RT}$, heated to $70{ }^{\circ} \mathrm{C}$ for $2 \mathrm{~h}$, and stored at $-20{ }^{\circ} \mathrm{C}$ for $15 \mathrm{~min}$. The sample mixtures were diluted with $0.8 \mathrm{~mL}$ of ethyl acetate, vortexed at RT, and centrifuged. Three xylan samples were treated analogously to determine the recovery rate (114.99\%), which was considered for calculation of the results.

The samples were transferred into $1.5 \mathrm{~mL} \mathrm{GC}$ vials and $1 \mu \mathrm{L}$ was injected (injector temperature: $260{ }^{\circ} \mathrm{C}$, split ratio of 10:1) into the GC-FID system (Agilent 7890B, Agilent Technologies Inc., Canada). For the analysis, a HP1 methyl siloxane column (Agilent 19091Z-413: $\quad 30 \mathrm{~m} * 320 \mu \mathrm{m} * 0.25 \mu \mathrm{m}$, Agilent Technologies Inc., USA) was used with $\mathrm{H}_{2}$ as carrier gas at a flow rate of $2 \mathrm{~mL} / \mathrm{min}$. Initially, the oven temperature was kept at $140{ }^{\circ} \mathrm{C}$ for $1 \mathrm{~min}$, then increased to $210{ }^{\circ} \mathrm{C}$ at a rate of $4 \mathrm{~K} / \mathrm{min}$, and further increased to $260{ }^{\circ} \mathrm{C}$ at a rate of $30 \mathrm{~K} / \mathrm{min}$ with a hold time of $5 \mathrm{~min}$. The detector temperature was kept at
$280{ }^{\circ} \mathrm{C}$. The FID temperature was maintained at $320{ }^{\circ} \mathrm{C}$ with a $\mathrm{H}_{2}$ flow of $30 \mathrm{~mL} / \mathrm{min}$. The retention time of the individual methyl glycosides was calibrated by means of commercially available standards of highest purity. The FID signal was evaluated utilizing Agilent ChemStation software (Agilent Technologies Inc., USA).

\section{Results and discussion}

Solid-state ${ }^{13} \mathrm{C}$ CP/MAS NMR spectroscopy is an excellent method to characterize the supramolecular assembly of cellulose polymer chains (French et al. 2018; Zugenmaier 2021). In contrast to crystallographic diffraction techniques, solid-state ${ }^{13} \mathrm{C}$ NMR spectroscopy requires no sample pretreatment. In solid state, the shift values are not only affected by the neighboring atoms in the molecule (as in solution state), but as well by the chemical environment generated by the supramolecular structure and the packing in the solid (Foston 2014). Thus, this method has become one of the standard techniques to investigate cellulosic materials, cellulose crystallites and their three-dimensional arrangement, and cellulose allomorphs. Especially, the $\mathrm{C} 4$ resonance (79-91 ppm) of celluloses contains this ultrastructural information without interference from neighboring resonances. In this study, paper samples immersed in transformer oil and subjected to $170{ }^{\circ} \mathrm{C}$ for up to 14 days were examined, applying established deconvolution models for the cellulose polymorph I. The contributions to the $\mathrm{C} 4$ resonances of pure cotton paper (WP), as reference material, and a paper from softwood Kraft pulp (SWKP) are shown in Fig. 1a and b. The types of the different contributors and their location in the crystallite bundles are schematically presented in Fig. 1c.

Generally, the C4 solid-state NMR resonances of cellulose are composed of one part representing the interior of crystallites (the range between $91 \mathrm{ppm}$ and the local minimum close to $86 \mathrm{ppm}$ ) and a second part representing crystallite surfaces, the range from the local minimum at 86-79 ppm) (Larsson et al. 1997; Newman 1998; Wickholm et al. 1998). The C4 resonance of the crystallite core ( $\mathrm{C}$ in Fig. 1c) consists of a signal attributed to cellulose allomorph $\mathrm{I} \alpha(\mathrm{I} \alpha)$, one from cellulose allomorph I $\beta$ (I $\beta)$, and a combined contribution from the allomorphs $\mathrm{I} \alpha$ and $\mathrm{I} \beta$ (I $\alpha \beta)$ 
(a) Whatman paper No. 1

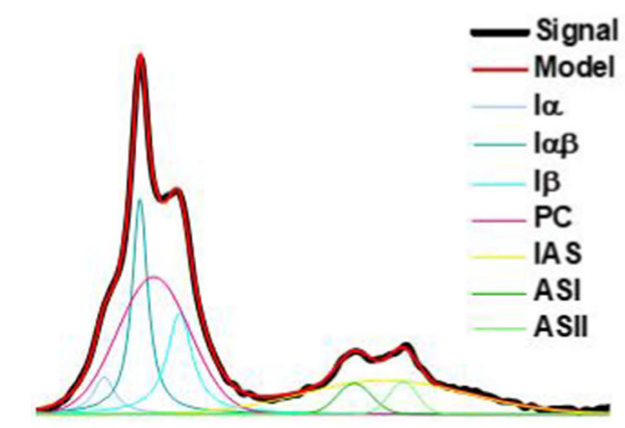

$\begin{array}{lllllllllllllllll}91 & 90 & 89 & 88 & 87 & 86 & 85 & 84 & 83 & 82 & 81 & 80 & 79\end{array}$ Chemical shift (ppm)

(b)

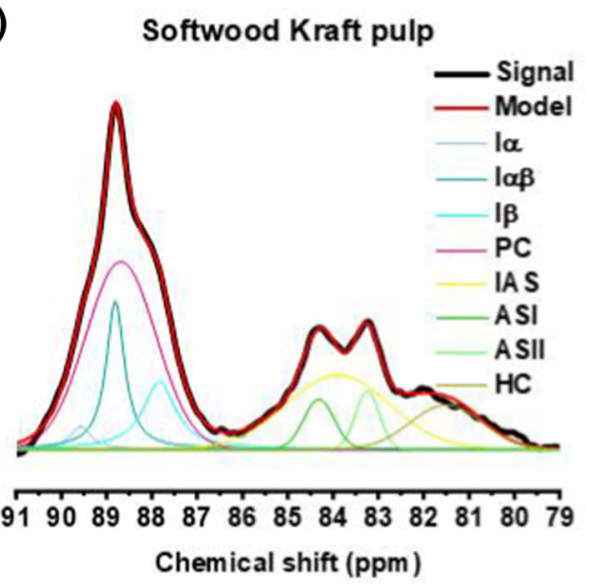

Fig. 1 C4 resonance in ${ }^{13} \mathrm{C} \mathrm{CP} / \mathrm{MAS}$ NMR spectra of reference material (a Whatman paper (WP), b Softwood Kraft paper (SWKP)) deconvoluted according to Wickholm et al. (1998) and Zuckerstätter et al. (2013), c Sketch of cellulose crystallite bundles including the different phases of the supramolecular cellulose structure contributing to the $\mathrm{C} 4$ resonance, based on

(Yamamoto and Horii 1993; Kono et al. 2003). A resonance assigned to a paracrystalline phase (PC in Fig. 1c) is superimposed (Larsson et al. 1997). $P C$ is a less ordered, crystalline phase characterized by imperfections; frequently described as the surface-near layer of crystallites. The $\mathrm{C} 4$ resonance part representing crystallite surfaces consists of two contributions from accessible crystallite surfaces (ASI and ASII, AS in Fig. 1c) and a broad signal assigned to inaccessible surfaces (IAS in Fig. 1c) (Wickholm et al. 1998). If hemicelluloses were present in the sample, an additional $\mathrm{C} 4$ resonance signal (HC) is contributing to the overall C4 peak shape (cf. Fig. 1b). Regarding (c)

(d)

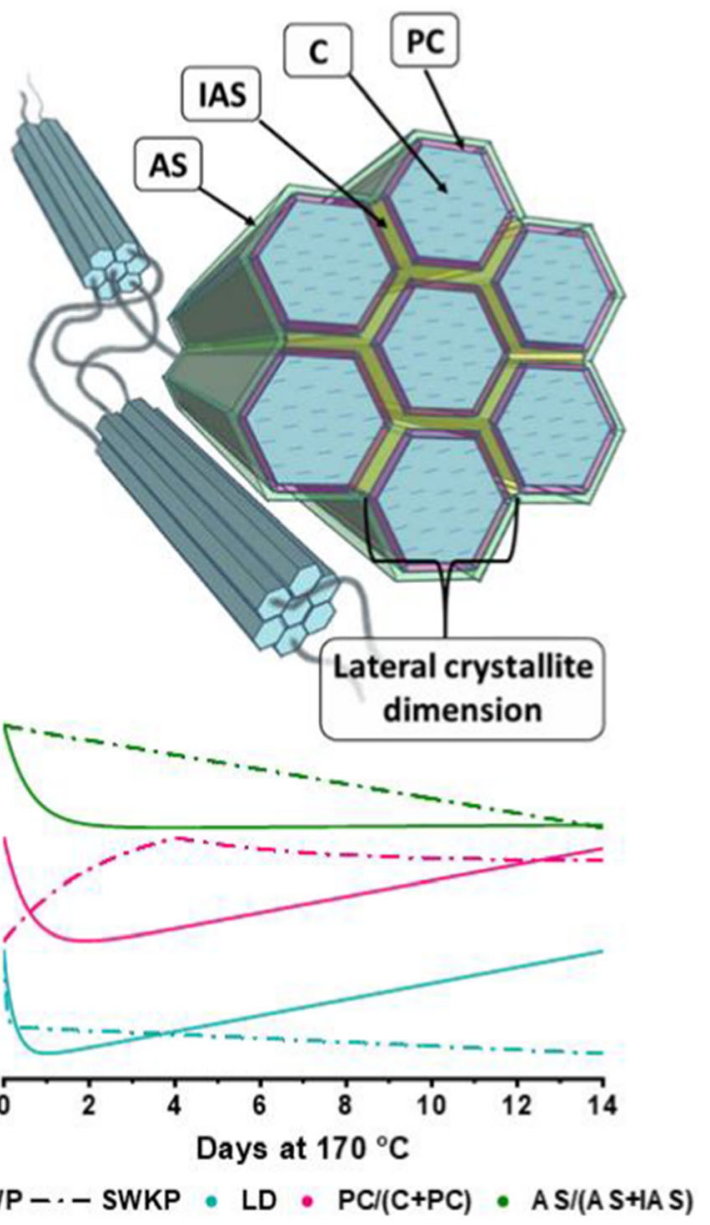

the work of Larsson and Westlund (2005), Zuckerstätter et al. (2013) and Oehme et al. (2015): crystalline core (C = I $\alpha+$ $\mathrm{I} \beta+\mathrm{I} \alpha \beta$ ), paracrystalline region (PC), accessible surface (ASI and ASII), inaccessible surface (IAS), $\mathbf{d}$ Normalized trendlines illustrating the major differences between WP and SWKP upon thermal treatments

accessibility to water molecules or other solvents, non-ordered, amorphous cellulose has similar properties as accessible crystallite surfaces (French et al. 2018), and is hence represented by ASI and ASII as well.

Before evaluating cellulose $\mathrm{C} 4$ resonances in ${ }^{13} \mathrm{C}$ CP/MAS NMR spectra of lignin-containing pulp samples, it must be assured that lignin-derived resonances do not distort the results. Therefore, a lignin sample was obtained from black liquor by means of acid precipitation and subsequent washing. The black liquor sample was taken from the same pulp mill where the used softwood Kraft pulp was produced. 
The resonance signal at $56 \mathrm{ppm}$ of the SWKP spectrum depicted in Fig. 2 (black line) originates from methoxyl groups of the residual lignin structure (Evans et al. 1995) and was used for superposition/ normalization of a ${ }^{13} \mathrm{C} \mathrm{CP/MAS} \mathrm{NMR} \mathrm{spectrum} \mathrm{of} \mathrm{the}$ isolated lignin (orange line) with the cellulose spectrum. No interference with the $\mathrm{C} 4$ signal was observed when the lignin spectrum was normalized (dash-dotted line, cf. Fig. 2) so it was assumed that the $\mathrm{C} 4$ resonance could be safely treated without considering any lignin contributions.

The samples investigated in this study were pure cellulose paper (WP) as reference and unbleached Kraft pulp (SWKP) used for insulation paper manufacture. Both sample series were fully immersed in degassed, dry transformer oil and subjected to $170{ }^{\circ} \mathrm{C}$ for up to 14 days and sampled in different intervals. This experimental setup allowed to track down thermally induced supramolecular changes and-in the case of the SWKP paper-alterations in the monosaccharide composition. After ageing, the oil was fully removed by accelerated solvent extraction (ASE) with $n$-heptane and ${ }^{13} \mathrm{C} \mathrm{CP} / \mathrm{MAS}$ NMR spectra were recorded of each sample. The spectra were imported into OriginPro 2020 and the $\mathrm{C} 4$ resonances were deconvoluted by non-linear least-squares curve fitting with the "Peak Analyzer" tool. Initial peak positions were defined according to Zuckerstätter et al.

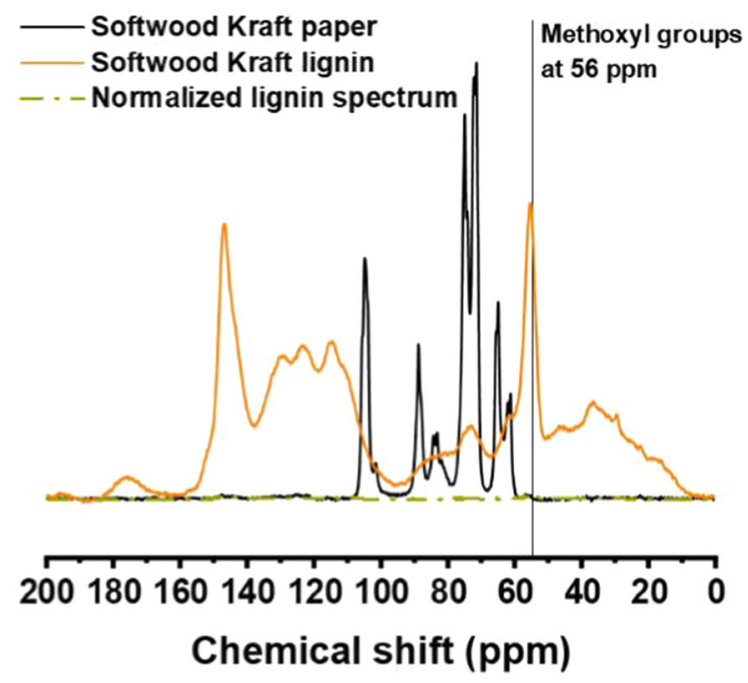

Fig. 2 Solid-state ${ }^{13} \mathrm{C} \mathrm{CP/MAS} \mathrm{NMR} \mathrm{spectra} \mathrm{of} \mathrm{softwood} \mathrm{Kraft}$ pulp and the corresponding isolated lignin, including a lignin spectrum normalized at the chemical shift of methoxyl groups at $56 \mathrm{ppm}$
(2013) and peak widths were constrained by using three times the standard deviation as reported by Wickholm et al. (1998) for Kraft pulp samples to calculate upper and lower limits. Line shapes were defined according to Wickholm et al. (1998) as well. For the ${ }^{13} \mathrm{C} \mathrm{CP/MAS} \mathrm{NMR} \mathrm{spectra} \mathrm{and} \mathrm{detailed} \mathrm{results}$ of the $\mathrm{C} 4$ deconvolution refer to the supplementary information (WP: Figures S1-S7 and Tables S1-S7, SWKP: Figures S8-S16 and Tables S8-S16). The NMR spectra in Figures S1-S16 indicated that the cellulose allomorph I was preserved throughout the ageing experiments. Peak positions and peak widths of the contributors to the $\mathrm{C} 4$ resonances are reported in Tables 1 and 2, as average values from the analysis of the WP sample series and the SWKP sample series, respectively.

At first, the crystallinity index $(C I)$ was calculated for each sample. $C I$ is the ratio of crystallite core resonances $(\mathrm{C})$ plus the PC signal divided by the sum of all signals contributing to the total $\mathrm{C} 4$ resonance. $\mathrm{HC}$ signals were not considered to calculate the $C I$ for SWKP samples $(\mathrm{I} \alpha+\mathrm{I} \alpha \beta+\mathrm{PC}+\mathrm{I} \beta+\mathrm{ASI}+$ IAS + ASII $=100 \%$ ) since the HC contribution to the signal does not originate from resonances of cellulose. The average surface layer distance $(d)$ was derived from the hexagonal 24 cellulose chain crystallite model proposed by Oehme et al. (2015). Subsequently, $C I$ and $d$ were used in Eq. (1) to obtain the lateral dimension of cellulose crystallites $(L D)$. Note that $d$ could also be derived from the 18 cellulose chains crystallite model. However, the differences are negligibly small. Moreover, according to literature, 18 cellulose chains seem to be the lower threshold for a crystallite to maintain its high-order characteristics (Nixon et al. 2016); Besides this, due to partial coalescence of adjacent crystallites this number would be easily surpassed (Newman et al. 2013). We thus concluded that it is acceptable to analyze our thermally stressed samples based on a hexagonal crystallite model composed of 24 cellulose chains across the section (cf. Fig. 1c).

The initial $L D$ of the WP sample was $6.95 \mathrm{~nm}$ and that of the SWKP sample $5.61 \mathrm{~nm}$. Previously, similar crystallite dimensions of comparable sample materials were determined by X-ray scattering (Newman 1999; Virtanen et al. 2015). Upon ageing at $170{ }^{\circ} \mathrm{C}$ both paper types exhibited a pronounced initial drop of the crystallite diameter within the first day (cf. Fig. 3 and Fig. 1d), which was more pronounced for the SWKP 
Table 1 Contributors to the $\mathrm{C} 4$ resonance in ${ }^{13} \mathrm{C} \mathrm{CP} /$ MAS NMR spectra of Whatman paper (WP)
Table 2 Contributors to the $\mathrm{C} 4$ resonance in ${ }^{13} \mathrm{C} \mathrm{CP} /$ MAS NMR spectra of Softwood Kraft paper (SWKP)

\begin{tabular}{llll}
\hline Peak & Shape & Position $(\mathrm{ppm})$ & FWHH $(\mathrm{ppm})$ \\
\hline Whatman paper $(W P)$ & & & \\
I $\alpha$ & Lorentz & $89.58( \pm 0.01)$ & $0.46( \pm 0.04)$ \\
I $\alpha \beta$ & $88.85( \pm 0.01)$ & $0.42( \pm 0.02)$ \\
PC & Lorentz & $88.45( \pm 0.06)$ & $1.86( \pm 0.04)$ \\
I $\beta$ & Gaussian & $88.03( \pm 0.01)$ & $0.67( \pm 0.02)$ \\
AS I & Lorentz & $84.35( \pm 0.03)$ & $0.82( \pm 0.02)$ \\
IAS & Gaussian & $83.80( \pm 0.10)$ & $4.39( \pm 0.32)$ \\
AS II & Gaussian & $83.36( \pm 0.03)$ & $0.75( \pm 0.02)$ \\
\hline
\end{tabular}

\begin{tabular}{llll}
\hline Peak & Shape & Position $(\mathrm{ppm})$ & FWHH $(\mathrm{ppm})$ \\
\hline Softwood Kraft paper $($ SWKP) & & & \\
I $\alpha$ & Lorentz & $89.52( \pm 0.06)$ & $0.71( \pm 0.06)$ \\
I $\alpha \beta$ & Lorentz & $88.82( \pm 0.01)$ & $0.47( \pm 0.02)$ \\
PC & Gaussian & $88.55( \pm 0.05)$ & $1.82( \pm 0.03)$ \\
I $\beta$ & Lorentz & $87.85( \pm 0.04)$ & $0.89( \pm 0.07)$ \\
AS I & Gaussian & $84.30( \pm 0.01)$ & $1.07( \pm 0.11)$ \\
IAS & Gaussian & $83.72( \pm 0.06)$ & $4.89( \pm 0.77)$ \\
AS II & Gaussian & $83.27( \pm 0.03)$ & $0.72( \pm 0.04)$ \\
HC & Gaussian & $81.83( \pm 0.13)$ & $1.52( \pm 0.40)$ \\
\hline
\end{tabular}

(a)

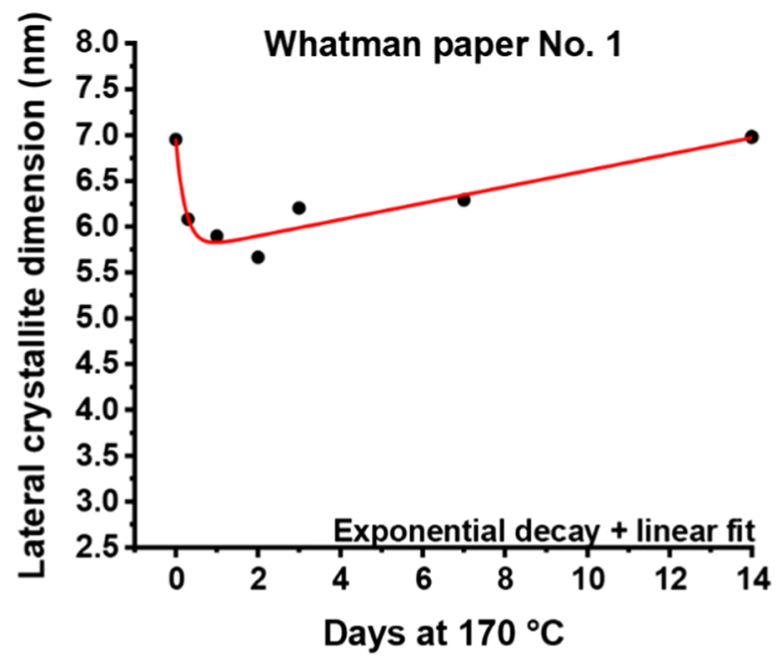

(b)

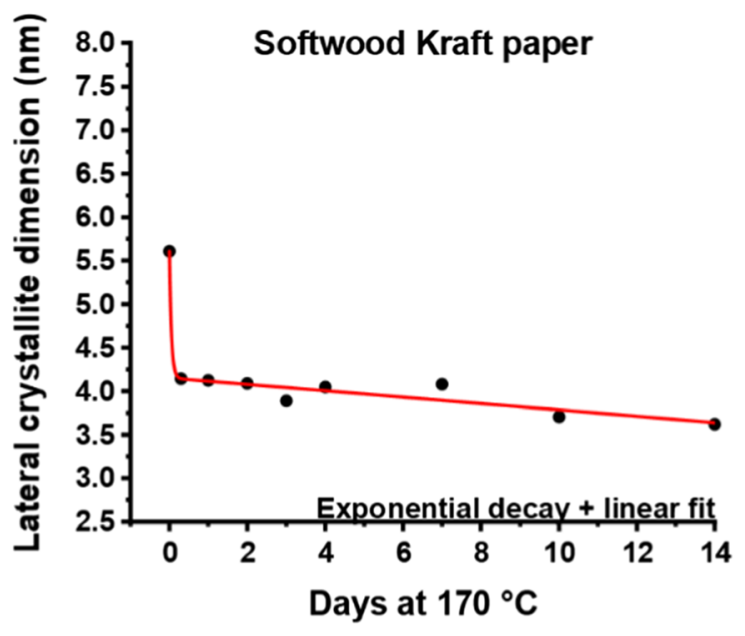

Fig. 3 Development of the lateral crystallite dimension $(L D)$ upon thermal aging. a Whatman paper (WP), b Softwood Kraft paper (SWKP)

ageing series. Already after about $8 \mathrm{~h}$ at $170{ }^{\circ} \mathrm{C}$, the $L D$ of SWKP went down to $4.14 \mathrm{~nm}$. Prolonging the exposure to $170{ }^{\circ} \mathrm{C}$ for up to 14 days, resulted in a slight further decrease of $L D$ following a roughly linear trend. The terminal $L D$ of SWKP was $3.62 \mathrm{~nm}$. This corresponds to an overall loss of about one third of the initial diameter. On the contrary, after the initial $L D$ drop of the pure cotton cellulose sample, with the 
minimum $L D$ of $5.67 \mathrm{~nm}$ being reached after 2 days, the WP sample showed increasing $L D$-values with a final $L D$ reaching the initial value again $\left(L D_{\mathrm{WP} 14}=6.98 \mathrm{~nm}\right)$.

Obvious differences regarding the changes in the supramolecular structure in dependence of the paper composition were also observed when the ratio between accessible crystallite surfaces and total crystallite surfaces was evaluated (cf. Fig. 4 and Fig. 1d). It was evident, that the initial reduction of AS signals in relation to the total surface signal (IAS + AS) was much stronger for samples exclusively composed of cellulose (WP). Up to an ageing duration of 2 days the ratio AS/(AS + IAS) for WP samples exhibited an exponential decay which was thereafter followed by a rather constant phase up to 14 days (cf. Fig. 4a). In contrast to WP, for SWKP samples the fraction of AS decreased in a roughly linear manner (cf. Fig. 4b). However, while the curve shape was different, the initial values and the final values after 14 days were very close to each other for both sample series.

Moreover, the PC signals in relation to the sum of all signals attributed to the crystallite interior $(\mathrm{C}+\mathrm{PC})$ developed in an opposite manner for WP and SWKP samples (cf. Fig. 3 and Fig. 1d). Whilst the PC fraction of WP samples was first decreasing within the first 2 days at $170{ }^{\circ} \mathrm{C}$, it exhibited a second phase of increasing PC intensities. The PC fraction of SWKP samples kept increasing during the first 4 days at $170{ }^{\circ} \mathrm{C}$ and then showed a slight reduction.

(a)

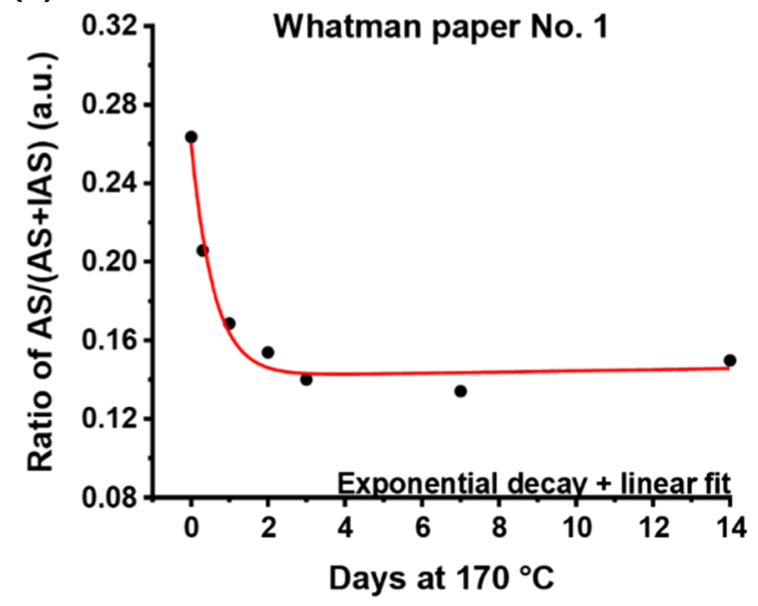

The results in Figs. 3a, 4a, and 5a clearly support hornification and coalescence of cellulose fibers for WP samples under the given elevated temperatures. This irreversible aggregation of cellulose fibrils is facilitated by high temperatures and acidic environments (Pönni et al. 2012) which is to be expected in thermally aged systems of oil immersed paper (Jusner et al. 2021). There is no exact definition of "hornification" and its different aspects are still under debate, but independently of whether hornification actually is to be defined as the formation of intra-fiber links (ester or hemiacetal/hemiketal) upon thermal stress (Fernandes Diniz et al. 2004) or the irreversible formation of intra-fiber hydrogen-bond networks (Kato and Cameron 1999), it most certainly results in reduced swelling of cellulose fibrils by water (i.e. reduced AS for water). An additional reason for the decreased AS might be a superficial deposition of hydrophobic paper decomposition products (e.g. furanoids, humins) on the crystallites. Furthermore, from 3 days at $170{ }^{\circ} \mathrm{C}$ onwards increasing cellulose crystallite diameters $(L D)$ were determined for WP samples. This could be explained by the phenomenon of twinned cellulose crystallites, which according to Newman et al. (2013) is to be defined as (partial) coalescence of pairs of adjacent crystallites along their axis. Upon reaggregation of dispersed TEMPO-oxidized cellulose nanofibers a similar phenomenon has been recently observed (Daicho et al. 2021). In that case, the recovery of the crystallite diameter was especially

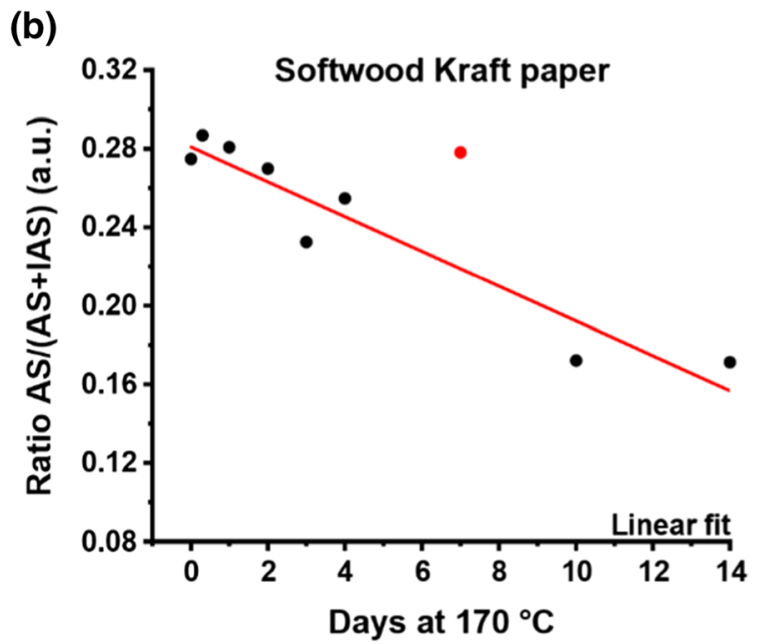

Fig. 4 Development of the signal corresponding to accessible surfaces (AS) related to the sum of the signals of accessible surfaces and inaccessible surface (IAS) upon thermal aging. a Whatman paper (WP), b Softwood Kraft paper (SWKP). Red symbol: obvious outlier 
(a)

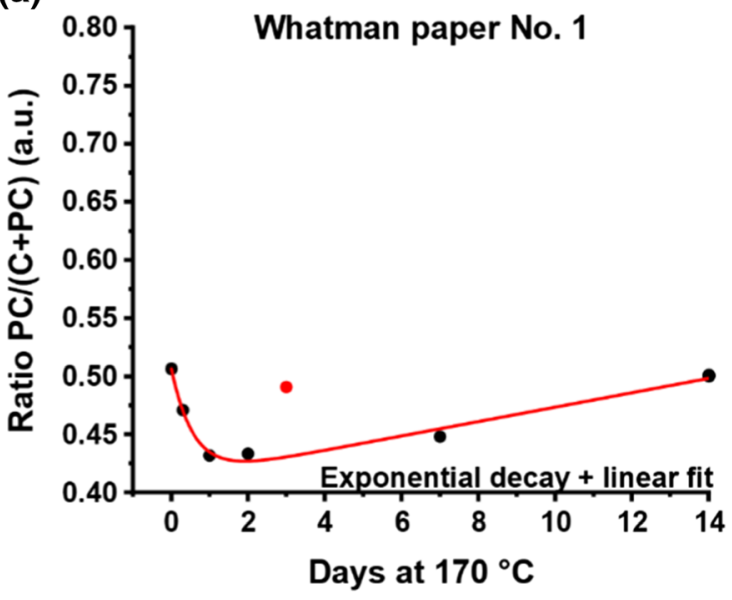

(b)

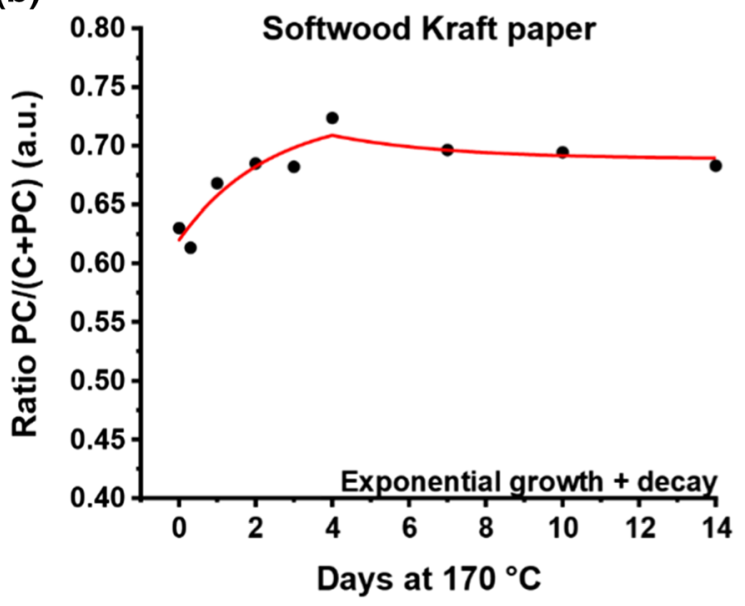

Fig. 5 Development of the ratio between paracrystalline signal contribution (PC) and sum of all signals assigned to the crystalline interior phase (C + PC), upon thermal aging. a Whatman paper (WP), b Softwood Kraft paper (SWKP). Red symbol: obvious outlier

well seen for the case of hydrothermally treated cellulose nanofiber films at $135^{\circ} \mathrm{C}$. Our experiments clearly demonstrate that such a recrystallization is also one of the consequences of thermal ageing of pure cellulose papers. This trend of growing $L D$ from 3 days onwards coincides with a phase of increasing $\mathrm{PC}$ fraction in relation to the total crystallite $\mathrm{C} 4$ signal (cf. Figs. 3a and 5a). Paracrystalline cellulose is a crystalline phase characterized by imperfections and a slightly higher mobility of cellulose polymers compared to those located in the perfectly crystalline core (Larsson et al. 1997; Ioelovich et al. 2010). Evidently, twinning and coalescence of cellulose crystallites does not result in the (re-)formation of crystalline core structures which could be clearly assigned either to cellulose allomorph I $\alpha$ or I $\beta$.

Compared to WP samples, SWKP samples exhibited a slower decrease of AS in relation to IAS (cf. Fig. 4) and showed no tendency towards twinning of cellulose crystallites (cf. Fig. 3). This is consistent with literature stating that the mechanisms defining the supramolecular cellulose arrangement at elevated temperatures strongly depend on the paper composition. Pure cotton cellulose is known to show a strong tendency towards hornification and coalescence of fibers (Pönni et al. 2012). Upon chemical and thermal treatments, for cellulosic material with increasing hemicellulose and lignin contents an increasing reluctance towards such supramolecular changes has been observed (Hult et al. 2001; Virtanen et al. 2008;
Wan et al. 2010). Furthermore, Wan et al. (2010) demonstrated that repeatedly recycled and dried cellulosic fibers of high hemicellulose contents better preserve mechanical properties and molecular structures than fibers of lower hemicellulose content. These observations may be a consequence of the location of hemicelluloses and lignin within softwood fibrils. Cellulose crystallites surrounded by hemicelluloses are arranged to bundles covered in a layer of lignin molecules (Terrett et al. 2019). Thus, reduced structural rearrangements of SWKP-samples seem plausible compared to WP. This partial preservation of the "original" supramolecular structure upon exposure to unintentional temperature rises might be another beneficial factor contributing to the surprisingly long service life of paper insulators in electrical power transformers. These insulators are preferably manufactured of unbleached softwood Kraft pulp which is characterized by a high hemicellulose content (cf. Fig. 7).

As mentioned before, ${ }^{13} \mathrm{C}$ CP/MAS NMR is an excellent method to assess the amounts of allomorphs $\mathrm{I} \alpha$ and I $\beta$ in cellulose I crystallites (Yamamoto and Horii 1993; Kono et al. 2003; Kono and Numata 2006). Deconvolution and evaluation of $C 4$ resonance indicated that changes of the allomorph composition occurred throughout the time of exposure to $170{ }^{\circ} \mathrm{C}$. Initially, when subjected to $170{ }^{\circ} \mathrm{C}$ cotton cellulose paper (WP) immersed in transformer oil showed a slight increase of the I $\alpha$ fraction (cf. Fig. 6a), and then 

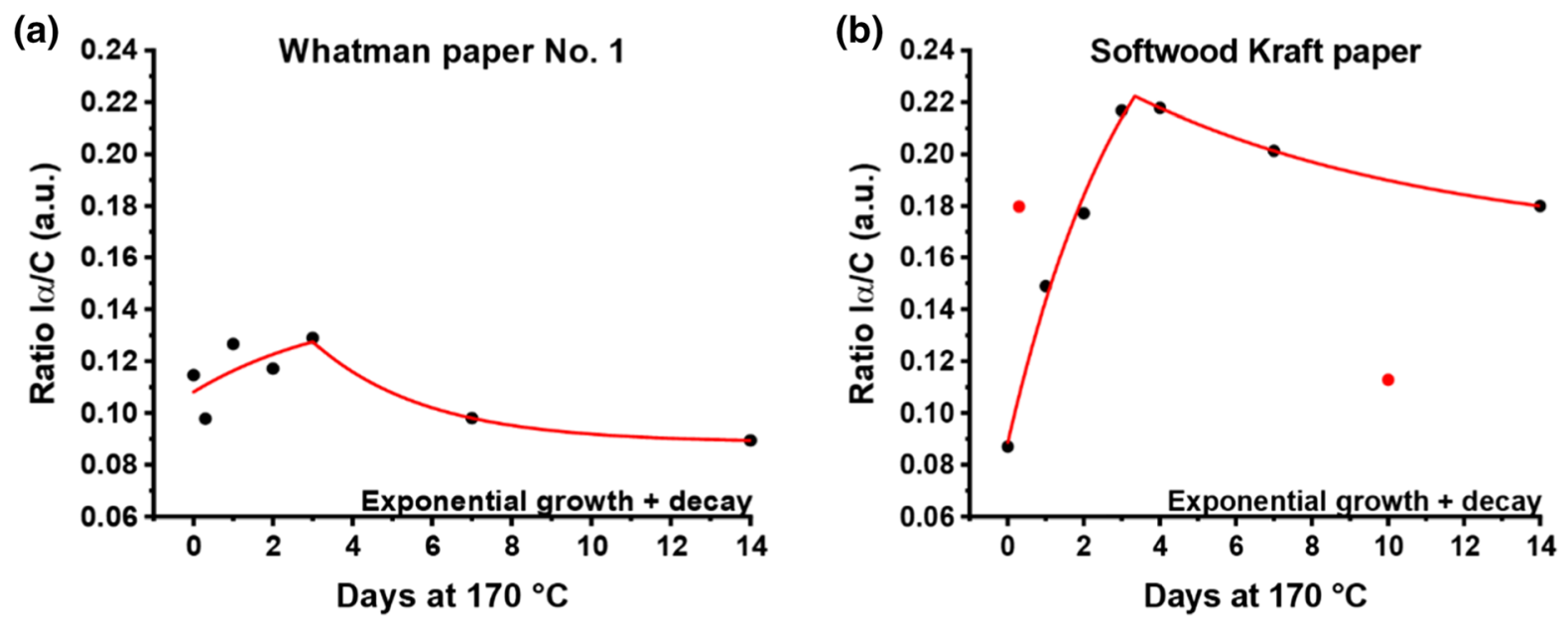

Fig. 6 Development of the ratio between cellulose allomorph I $\alpha$ and the total of signals attributed to the crystalline core $(C=I \alpha+I \beta+I \alpha \beta)$, upon thermal aging. a Whatman paper (WP), b Softwood Kraft paper (SWKP). Red symbol: obvious outlier

the I $\alpha$ signal intensity decreased again until after 14 days it fell below the initial value. A similar trend was observed for paper samples made of softwood Kraft pulp (SWKP, Fig. 6b). However, the intensity of the initial increase was much more pronounced. This phase of an increasing I $\alpha$ fraction was observed whilst the $L D s$ of both sample types dropped significantly (cf. Fig. 3).

The development of the I $\alpha$ signal intensity in relation to the total crystalline core signals $(\mathrm{C}=\mathrm{I} \alpha+$ $\mathrm{I} \beta+\mathrm{I} \alpha \beta)$ up to 3 days at $170{ }^{\circ} \mathrm{C}$ might be a consequence of a stronger involvement of the allomorph I $\beta$ in thermally induced processes affecting the supramolecular structure. Since the crystallite dimensions do not stay constant throughout aging, an initial preferential decomposition of I $\beta$ seems possible. This may be facilitated by a distorted crystallite geometry due to thermally induced changes of the unit cell parameters (Hori and Wada 2005) and result in an increased accessibility of cellulose polymers of allomorph I $\beta$ to acid catalyzed hydrolysis and thermal dehydration. Hori and Wada (2005) demonstrated that cellulose allomorph $\mathrm{I} \beta$ found in tension wood samples of Populus maximowiczii Henry A. strongly expands in an anisotropic manner upon heating from room temperature up to $250{ }^{\circ} \mathrm{C}$ and undergoes a phase transition at $180{ }^{\circ} \mathrm{C}$ into a high temperature intermediate form of cellulose I. To the best of our knowledge, a thermally induced solid-state transformation of cellulose allomorph I $\beta$ to allomorph $\mathrm{I} \alpha$ has never been observed for native cellulose samples. On the contrary, transformation of the cellulose allomorph I $\alpha$ to allomorph I $\beta$ has been detected for highly crystalline and purified cellulose I samples when subjected to hydrothermal treatment at temperatures up to $280{ }^{\circ} \mathrm{C}$ (Horii et al. 1987; Sugiyama et al. 1990; Debzi et al. 1991; Yamamoto and Horii 1993). It seems plausible that such a transformation of allomorph I $\alpha$ to allomorph I $\beta$ takes place also in the later phase of our aging experiment (from 3 to 14 days at $170{ }^{\circ} \mathrm{C}$ ). Debzi et al. (1991) reasoned that smaller cellulose crystallite dimensions would be beneficial for increased mobility of cellulose chains within the crystallite which, consequently, would facilitate the solid-state allomorph transformation. There is some indication that this conversion proceeds via the afore mentioned metastable high temperature crystallite form (Wada et al. 2003; Matthews et al. 2012) and that such a high temperature intermediate of cellulose I is formed at lower temperatures for samples of smaller crystallite dimensions (Wada 2002; Hori and Wada 2005). This may explain the more pronounced trend of the I $\alpha$ signal increase for SWKP compared to WP (cf. Fig. 6) since the initial $L D$ is much lower for SWKP (cf. Fig. 3). However, based on our findings it is not possible to characterize these interesting changes of the allomorph $\mathrm{I} \alpha-\mathrm{I} \beta$ composition in more details, which is left to future studies.

Relative changes of the hemicellulose content of lignocellulosic samples can be assessed based on the $\mathrm{C} 4$ resonance of ${ }^{13} \mathrm{C} \mathrm{CP} / \mathrm{MAS} \mathrm{NMR}$ spectra. The relative intensity of the $\mathrm{HC}$ signal contributor was 
(a)

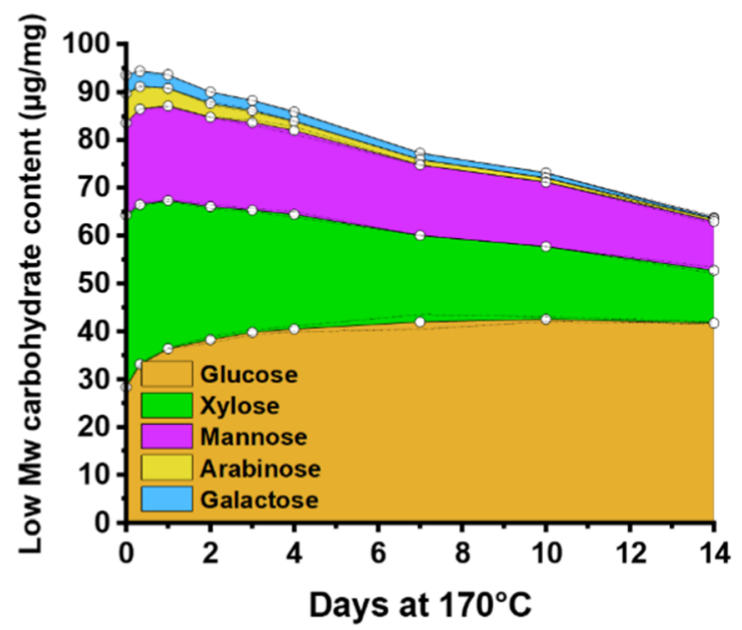

Fig. 7 The hemicellulose $\mathrm{C} 4$ resonance (HC) compared to the changes of the sample's carbohydrate composition upon thermal aging. a Absolute values obtained by acidic methanolysis, $\mathbf{b}$ The

compared to results obtained by acidic methanolysis (cf. Fig. 7). Acidic methanolysis is an excellent method for cleaving glycosidic linkages of hemicellulose carbohydrates without subsequent degradation of the released residues (Bertaud et al. 2002; Becker et al. 2021). An exponential decay fit through the relative intensities of the $\mathrm{HC}$ signal correlated very well with the relative curves for the amounts of arabinose, galactose, and xylose residues, while a rather poor correlation with mannose was found. The opposite trend for glucose is easily explained by the increasing accessibility and resulting higher yields in methanolysis (Becker et al. 2021). Based on these findings, it can be concluded that it is valid to assess relative contents of xylan in aged paper samples based on the HC signal intensity.

\section{Conclusions}

Deconvolution of the $\mathrm{C} 4$ resonance of ${ }^{13} \mathrm{C} \mathrm{CP} / \mathrm{MAS}$ NMR spectra of thermally aged paper samples clearly showed that hornification and coalescence of cellulose fibrils are the consequences of an unintentional temperature rise in insulator papers in electrical power transformers. Furthermore, it was evident that the evolution of the supramolecular structure strongly depended on the sample composition (for general trends, cf. Fig. 1d). Unbleached softwood Kraft paper (b)

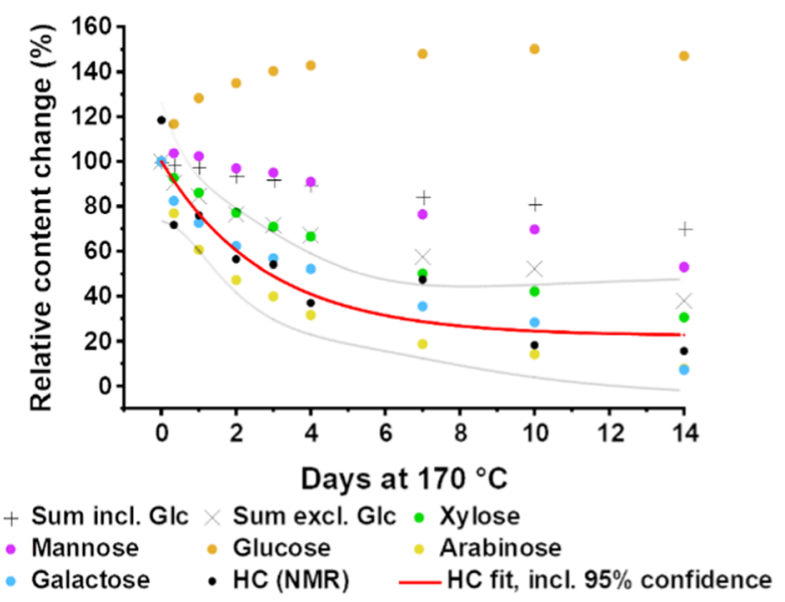

relative change of low $\mathrm{Mw}$ carbohydrate composition compared to the relative intensity of the $\mathrm{HC} \mathrm{C} 4$ resonance; an exponential decay was applied as fitting function

(SWKP) samples would initially better preserve their initial structure than cotton cellulose (WP). Nonetheless, in both cases, changes in the supramolecular structure occurred at prolonged exposure to $170{ }^{\circ} \mathrm{C}$, including phase transitions between the allomorphs $\mathrm{I} \alpha$ and I $\beta$ within the individual crystallites. For both sample sets an initial increase of the fraction I $\alpha$ was observed which declined again after 3-4 days. The reasons for this observation are currently studied. The hemicellulose contributor to the $\mathrm{C} 4$ resonance signal was found to be a valid indicator for assessing the xylan content changes in thermally aged paper samples. Generally, we can confirm that ${ }^{13} \mathrm{C} \mathrm{CP} / \mathrm{MAS}$ NMR spectroscopy is a highly suitable tool to study the effects of thermal stress on cellulose and paper samples. We hope that the results presented and the discussion in this work will contribute to a better understanding of the solid-state changes in the special case of thermal aging of insulation papers, but also of thermally stressed papers in general.

Acknowledgments We would like to thank the University of Natural Resources and Life Sciences (BOKU), Vienna, Mondi Frantschach $\mathrm{GmbH}$, and the Austrian State of Lower Austria for their financial support in the framework of the Austrian Biorefinery Center Tulln (ABCT).

Authors' contributions PJ, AP, and TR contributed to the study conception and design. Material preparation, data collection and analysis were performed by all authors. The first draft of the manuscript was written by PJ and TR and all 
authors commented on previous versions of the manuscript. All authors read and approved the final manuscript.

Funding Open access funding provided by University of Natural Resources and Life Sciences Vienna (BOKU). The financial support by the Austrian Biorefinery Center Tulln $(\mathrm{ABCT})$ is gratefully acknowledged.

Data availability Data is available from the authors upon reasonable request.

Code availability Not applicable.

\section{Declarations}

Conflict of interest The authors declare that they have no conflict of interest.

Open Access This article is licensed under a Creative Commons Attribution 4.0 International License, which permits use, sharing, adaptation, distribution and reproduction in any medium or format, as long as you give appropriate credit to the original author(s) and the source, provide a link to the Creative Commons licence, and indicate if changes were made. The images or other third party material in this article are included in the article's Creative Commons licence, unless indicated otherwise in a credit line to the material. If material is not included in the article's Creative Commons licence and your intended use is not permitted by statutory regulation or exceeds the permitted use, you will need to obtain permission directly from the copyright holder. To view a copy of this licence, visit http://creativecommons.org/licenses/by/4.0/.

\section{References}

Arroyo-Fernandez OH, Fofana I, Jalbert J, Rodriguez E, Rodriguez LB, Ryadi M (2017) Assessing changes in thermally upgraded papers with different nitrogen contents under accelerated aging. IEEE Trans Dielectr Electr Insul 24:1829-1839

Atalla RH, Vanderhart DL (1984) Native cellulose: a composite of two distinct crystalline forms. Science 223:283

Balakshin MY, Capanema EA (2015) Comprehensive structural analysis of biorefinery lignins with a quantitative $13 \mathrm{C}$ NMR approach. RSC Adv 5:87187-87199

Becker M, Ahn K, Bacher M, Xu C, Sundberg A, Willför S, Rosenau T, Potthast A (2021) Comparative hydrolysis analysis of cellulose samples and aspects of its application in conservation science. Cellulose 28:8719-8734

Bertaud F, Sundberg A, Holmbom B (2002) Evaluation of acid methanolysis for analysis of wood hemicelluloses and pectins. Carbohydr Polym 48:319-324

Chrapava S, Touraud D, Rosenau T, Potthast A, Kunz W (2003) The investigation of the influence of water and temperature on the LiCl/DMAc/cellulose system. Phys Chem Chem Phys 5:1842-1847
Daicho K, Kobayashi K, Fujisawa S, Saito T (2021) Recovery of the irreversible crystallinity of nanocellulose by crystallite fusion: a strategy for achieving efficient energy transfers in sustainable biopolymer skeletons. Ang Chem Int Ed Engl 60:24630-24636

Debzi E, Chanzy H, Sugiyama J, Tekely P, Excoffier G (1991) The $\mathrm{I} \alpha \rightarrow \mathrm{I} \beta$ transformation of highly crystalline cellulose by annealing in various mediums. Macromolecules 24:6816-6822

Emsley AM, Stevens GC (1994a) Kinetics and mechanisms of the low-temperature degradation of cellulose. Cellulose 1:26-56

Emsley AM, Stevens GC (1994b) Review of chemical indicators of degradation of cellulosic electrical paper insulation in oil-filled transformers. IEE Proc Sci Meas Technol 141:324-334

Emsley A, Xiao X, Heywood R, Ali M (2000a) Degradation of cellulosic insulation in power transformers. Part 2: formation of furan products in insulating oil. IEE Proc Sci Meas Technol 147:110-114

Emsley AM, Ali M, Heywood RJ (2000b) A size exclusion chromatography study of cellulose degradation. Polymer 41:8513-8521

Evans R, Newman RH, Roick UC, Suckling ID, Wallis AFA (1995) Changes in cellulose crystallinity during kraft pulping-comparison of infrared, x-ray-diffraction and solid-state nmr results. Holzforschung 49:498-504

Fernandes Diniz JMB, Gil MH, Castro JAAM (2004) Hornification-its origin and interpretation in wood pulps. Wood Sci Technol 37:489-494

Foston M (2014) Advances in solid-state NMR of cellulose. Curr Opin Biotechnol 27:176-184

French AD, Pérez S, Bulone V, Rosenau T, Gray D (2018) Cellulose. In: Mark HF (ed) Encyclopedia of polymer science and technology. Wiley, Hoboken, pp 1-69

Hori R, Wada M (2005) The thermal expansion of wood cellulose crystals. Cellulose 12:479

Horii F, Yamamoto H, Kitamaru R, Tanahashi M, Higuchi T (1987) Transformation of native cellulose crystals induced by saturated steam at high temperatures. Macromolecules 20:2946-2949

Hult EL, Larsson PT, Iversen T (2001) Cellulose fibril aggregation-an inherent property of kraft pulps. Polymer 42:3309-3314

Ioelovich M, Leykin A, Figovsky O (2010) Study of cellulose paracrystallinity. BioResources 5:15

Jalbert J, Rodriguez-Celis E, Duchesne S, Morin B, Ryadi M, Gilbert R (2014) Kinetics of the production of chain-end groups and methanol from the depolymerization of cellulose during the ageing of paper/oil systems. Part 3: extension of the study under temperature conditions over $120^{\circ} \mathrm{C}$. Cellulose 22:829-848

Jusner P, Schwaiger E, Potthast A, Rosenau T (2021) Thermal stability of cellulose insulation in electrical power transformers-a review. Carbohydr Polym 252:117196

Kato KL, Cameron RE (1999) A review of the relationship between thermally-accelerated ageing of paper and hornification. Cellulose 6:23-40

Kim UJ, Eom SH, Wada M (2010) Thermal decomposition of native cellulose: influence on crystallite size. Polym Degrad Stab 95:778-781 
Kono H, Numata Y (2006) Structural investigation of cellulose I $\alpha$ and I $\beta$ by $2 D$ RFDR NMR spectroscopy: determination of sequence of magnetically inequivalent D-glucose units along cellulose chain. Cellulose 13:317-326

Kono H, Erata T, Takai M (2003) Determination of the throughbond carbon-carbon and carbon-proton connectivities of the native celluloses in the solid state. Macromolecules 36:5131-5138

Larsson PT, Westlund PO (2005) Line shapes in CP/MAS ${ }^{13} \mathrm{C}$ NMR spectra of cellulose I. Spectrochim Acta A Mol Biomol Spectr 62:539-546

Larsson PT, Wickholm K, Iversen T (1997) A CP/MAS ${ }^{13} \mathrm{C}$ NMR investigation of molecular ordering in celluloses. Carbohydr Res 302:19-25

Larsson PT, Hult EL, Wickholm K, Pettersson E, Iversen T (1999) CP/MAS ${ }^{13}$ C-NMR spectroscopy applied to structure and interaction studies on cellulose I. Solid State Nucl Magn Reson 15:31-40

Li Y, Zhou K, Li ZR, Zhang QG (2020) Research on the electrical aging characteristics of oil-impregnated pressboard under partial discharges. IEEE Trans Dielectr Electr Insul 27:42-48

Liebner F, Ebner G, Becker E, Potthast A, Rosenau T (2010) Thermal aging of 1-alkyl-3-methylimidazolium ionic liquids and its effect on dissolved cellulose. Holzforschung 64:161-166

Lundgaard LE, Hansen W, Linhjell D, Painter TJ (2004) Aging of oil-impregnated paper in power transformers. IEEE Trans Power Deliv 19:230-239

Matthews JF, Himmel ME, Crowley MF (2012) Conversion of cellulose I $\alpha$ to I $\beta$ via a high temperature intermediate (IHT) and other cellulose phase transformations. Cellulose 19:297-306

Newman RH (1998) Evidence for assignment of ${ }^{13} \mathrm{C}$ NMR signals to cellulose crystallite surfaces in wood, pulp and isolated celluloses. Holzforschung 52:157-159

Newman RH (1999) Estimation of the lateral dimensions of cellulose crystallites using ${ }^{13} \mathrm{C}$ NMR signal strengths. Solid State Nucl Magn Reson 15:21-29

Newman RH, Hill SJ, Harris PJ (2013) Wide-angle x-ray scattering and solid-state nuclear magnetic resonance data combined to test models for cellulose microfibrils in mung bean cell walls. Plant Physiol 163:1558-1567

Nixon BT, Mansouri K, Singh A, Du J, Davis JK, Lee JG, Slabaugh E, Vandavasi VG, O'Neill H, Roberts EM, Roberts AW, Yingling YG, Haigler CH (2016) Comparative structural and computational analysis supports eighteen cellulose synthases in the plant cellulose synthesis complex. Sci Rep 6:28696

Oehme DP, Downton MT, Doblin MS, Wagner J, Gidley MJ, Bacic A (2015) Unique aspects of the structure and dynamics of elementary I $\beta$ cellulose microfibrils revealed by computational simulations. Plant Physiol 168:3-17

Pönni R, Vuorinen T, Kontturi E (2012) Proposed nano-scale coalescence of cellulose in chemical pulp fibers during technical treatments. BioResources 7(4):6077-6108

Potthast A, Rosenau T, Sartori J, Sixta H, Kosma P (2002) Hydrolytic processes and condensation reactions in the cellulose solvent system $N, N$-dimethylacetamide/lithium chloride. Polymer 44(1):7-17
Prevost TA, Oommen TV (2006) Cellulose insulation in oilfilled power transformers: Part I-history and development. IEEE Electr Insul Mag 22:28-35

Rosenau T, Potthast A, Kosma P, Chen CL, Gratzl JS (1999) Autocatalytic decomposition of $N$-methylmorpholine- $N$ oxide Induced by Mannich intermediates. J Org Chem 64:2166-2167

Rosenau T, Potthast A, Milacher W, Hofinger A, Kosma P (2004) Isolation and identification of residual chromophores in cellulosic materials. Polymer 45(19):6437-6443

Scheirs J, Camino G, Tumiatti W, Avidano M (1998) Study of the mechanism of thermal degradation of cellulosic paper insulation in electrical transformer oil. Angew Makromol Chem 259:19-24

Soares S, Ricardo NMPS, Heatley F, Rodrigues E (2001) Low temperature thermal degradation of cellulosic insulating paper in air and transformer oil. Polym Int 50:303-308

Sugiyama J, Okano T, Yamamoto H, Horii F (1990) Transformation of Valonia cellulose crystals by an alkaline hydrothermal treatment. Macromolecules 23:3196-3198

Sundberg A, Sundberg K, Lillandt C, Holmhom B (1996) Determination of hemicelluloses and pectins in wood and pulp fibres by acid methanolysis and gas chromatography. Nordic Pulp Pap Res J 11:216-219

Terrett OM, Lyczakowski JJ, Yu L, Iuga D, Franks WT, Brown SP, Dupree R, Dupree P (2019) Molecular architecture of softwood revealed by solid-state NMR. Nat Commun $10: 4978$

Vanderhart DL, Atalla RH (1984) Studies of microstructure in native celluloses using solid-state carbon-13 NMR. Macromolecules 17:1465-1472

Virtanen T, Maunu SL, Tamminen T, Hortling B, Liitiä T (2008) Changes in fiber ultrastructure during various kraft pulping conditions evaluated by ${ }^{13} \mathrm{C}$ CPMAS NMR spectroscopy. Carbohydr Polym 73:156-163

Virtanen T, Penttilä PA, Maloney TC, Grönqvist S, Kamppuri T, Vehviläinen M, Serimaa R, Maunu SL (2015) Impact of mechanical and enzymatic pretreatments on softwood pulp fiber wall structure studied with NMR spectroscopy and X-ray scattering. Cellulose 22:1565-1576

Wada M (2002) Lateral thermal expansion of cellulose I $\beta$ and III polymorphs. J Polym Sci B Polym Phys 40:1095-1102

Wada M, Kondo T, Okano T (2003) Thermally induced crystal transformation from cellulose $\mathrm{I} \alpha$ to $\mathrm{I} \beta$. Polym $\mathrm{J}$ 35:155-159

Wan J, Wang Y, Xiao Q (2010) Effects of hemicellulose removal on cellulose fiber structure and recycling characteristics of eucalyptus pulp. Biores Technol 101:4577-4583

Wickholm K, Larsson PT, Iversen T (1998) Assignment of noncrystalline forms in cellulose I by CP/MAS ${ }^{13} \mathrm{C}$ NMR spectroscopy. Carbohydr Res 312:123-129

Yamamoto H, Horii F (1993) CPMAS carbon-13 NMR analysis of the crystal transformation induced for Valonia cellulose by annealing at high temperatures. Macromolecules 26:1313-1317

Yamamoto H, Horii F, Odani H (1989) Structural changes of native cellulose crystals induced by annealing in aqueous alkaline and acidic solutions at high temperatures. Macromolecules 22:4130-4132 
Zuckerstätter G, Schild G, Wollboldt P, Röder T, Weber HK, Sixta H (2009) The elucidation of cellulose supramolecular structure by ${ }^{13} \mathrm{C}$ CP-MAS NMR. Lenzing Ber 87:38-46

Zuckerstätter G, Terinte N, Sixta H, Schuster KC (2013) Novel insight into cellulose supramolecular structure through ${ }^{13} \mathrm{C}$ CP-MAS NMR spectroscopy and paramagnetic relaxation enhancement. Carbohydr Polym 93:122-128
Zugenmaier P (2021) Order in cellulosics: Historical review of crystal structure research on cellulose. Carbohydr Polym 254:117417

Publisher's Note Springer Nature remains neutral with regard to jurisdictional claims in published maps and institutional affiliations. 